containing 37.28 per cent. $\mathrm{Zn},{ }^{1}$ but the better way is to ignite and weigh as $\mathrm{Zn}_{2} \mathrm{P}_{2} \mathrm{O}_{7}$, containing 42.77 per cent. $\mathrm{Zn}$. In this case the filter-paper should be burned first to ash, then the ash and dried precipitate ignited gently at first, then for a few minutes at a bright red heat.

The flocculent $\mathrm{ZnNH}_{4} \mathrm{PO}_{4}+\mathrm{H}_{2} \mathrm{O}$ is very soluble in the mineral acids as well as in ammonia, but after crystallization it is much less soluble in the latter. It is only slightly soluble in acetic acid; an excess of I cc. in IOO cc. of solution does not dissolve an appreciable quantity. It is somewhat soluble in all ammonium salts, if only a small excess of phosphate is present. The addition of I cc. of a Io per cent. solution of sodium ammonium phosphate for each 0.005 gram of zinc is sufficient to entirely prevent its solution in ammonium chloride or sulphate, or in the acetate, unless the latter is present in enormous quantity. It is, however, always slightly soluble in the oxalate. Therefore, for very accurate work, lime and magnesia, if present in the zinc solution, are preferably separated together as phosphates, after adding a large excess of ammonia and reprecipitating; then the combined filtrates are to be slightly acidulated and proceeded with as above. The crystalline zinc ammonium phosphate is quite insoluble in hot or cold water.

For this elegant and accurate, but too little known, method I am indebted to Mr. Geo. C. Stone, who has carefully worked out its details, including the properties of the precipitate. Hundreds of filtrates from zinc phosphate, separated as described, have been tested by him with ammonium sulphide, without showing zinc.

\title{
THE ORGANIC MATTER IN SOILS AND SUBSOILS.
}

By F. K. Cameron and J. F. Breazeale.

Received September 16, 1903 .

\section{INTRODUCTION.}

THE relative amount of organic matter in a soil or subsoil has long been regarded as an important characteristic. Popularly, and with some reason, it has been generally held to furnish an indication of the fertility of a soil. It has a real importance, since it affects the texture or structure and water-holding capacity of

1 It can also be accurately titrated with ferrocyanide after solution in hydrochloric acid with addition of ammonium chloride. Also, according to P. H. Walker (This Journal, a3, 468), its zinc content may be determined alkalimetrically. 
the soil, serves, in part at least, as a carrier of plant food, and also serves as a host medium for various organisms essential to the soil's fertility.

It has long been recognized, moreover, that the exact determination of the organic matter in a soil sample is exceedingly difficult, taxing the skill and ingenuity of analysts to the utmost. Nevertheless, so important has this determination been regarded that many experiments have been made to find either a ready method for making it, or at least one which would yield a conventional result, and which might safely be regarded as an approximation of the truth.

To this end, three general methods have found favor:

I. The "loss on ignition" method.

II. The humus method.

III. The combustion method.

The first, or "loss on ignition" method, has probably been the most used. It consists essentially in burning out the organic matter in a sample previously dried or freed from hydroscopic moisture, and taking the difference in weight before and after ignition as the weight of organic matter originally present. The method is a rapid one, and easily manipulated, but is open to the serious objection that the high temperature generally required to effect a thorough combustion of the organic matter is sufficient to drive off from the sample much water, either of "crystallization," or of "constitution." In fact, a considerable number of the minerals to be found in most soils contain hydrogen as an essential constituent, and yield water, on severe ignition, which is not replaced by the subsequent treatment with the ammonium carbonate solution or moist carbon dioxide. The amount of water thus eliminated frequently exceeds the amount of organic matter actually present, as is strikingly illustrated by the figures given in Table III. Moreover, as will be brought out more fully at another point, a by no means negligible amount of carbon clioxide, other than that combined as carbonates of the alkaline earths, is frequently eliminated by severe ignition, and not replaced by the subsequent recarbonation method.

The second method is based upon the well-known views of Grandeau as to the importance of the matiére noiré or humus in the soil. It makes no pretense of giving the total amount of organic matter present, even excepting undecayed twigs, roots, 
and other obviously irrelevant substances. To this method, it may be objected that it is not generally agreed that the humus thus estimated is the only part of the organic matter valuable in a soil. And further, the ammonia solutions generally used very thoroughly break up the flocculation of the clay particles in the soil, so that a considerable amount of this mineral material is, of necessity, withdrawn and dried with the humus. On ignition, if it is necessary to raise the temperature materially, a large error may be introduced by loss of water from the clay, which is estimated as part of the humus. ${ }^{1}$

The third or combustion method consists in burning the organic matter, either in a tube with a combustion furnace, or by powerful oxidizing agencies, such as chromic acid or potassium permanganate, collecting and determining the carbon dioxide liberated by some appropriate mechanism, and then computing the organic matter from the carbon dioxide found by means of a conventional factor. The most obvious objection which may be urged against these combustion methods is in the use of this factor. On the authority of Wolf, van Bemmelen and Wollny, the most popular usage is to multiply the amount of carbon dioxide found by the factor $0.47 \mathrm{I}$. This factor seems to be based on the assumption made as a result of Wollny's well-known investigations that the percentage of carbon in the organic matter, or rather humus of the soil, varies but little from $5^{6}$ per cent. Wiley, however, states that it may vary between the wide limits, 42 and 72 per cent. An investigation of this point with typical soils of the United States will be described at another place in this paper.

COMPARISON OF THE ORGANIC MATTER IN SOILS, AND SUBSOILS.

For certain lines of work being carried on in this Bureau, it is desirable to have accurate determinations of the organic matter in soils and subsoils. It has been the practice here to make determinations of the loss on ignition for this purpose. While this practice has long. been felt to be far from satisfactory, it has become especially so recently, when it was found that the results thus obtained must, in many cases, be very misleading, and un-

1 In this connection, see Frear: Bull. 67, Bureau of Chemistry, U. S. Department of Agriculture, p. 40.

2 Wiley's "Principles and Practice of Agricultural Chemical Analysis," Vol. I. A complete historical account of this subject will be found in the work cited. 
suited even for comparative purposes. In the course of the field work of I900, there were eighty-four cases submitted to the laboratory in which the organic matter or loss on ignition was desired in both soil and corresponding subsoil. In thirty-two of these cases, the loss on ignition method showed larger figures for the subsoils than for the corresponding soils, and often very much larger figures. It was obviously certain, in some of these cases, that the figures obtained could not give a true comparison between the soil and subsoil. Inspection did not show that this peculiarity belonged to any particular class of soils, nor did their physical characteristics throw any light upon it. The problem was then referred to the laboratory, and it was determined to compare the various methods which have been suggested, not only as to the probability of organic matter predominating in the soil or subsoil, but to obtain a procedure which would lead to more satisfactory results and, at the same time. be sufficiently rapid to meet the considerable volume of such work incident " the Bureau's investigations.

SAMPLES SELECTED FOR INVESTIGATION.

For this purpose three soils and their corresponding subsoils were selected. They were taken somewhat at random, except for the one condition that the subsoils selected had yielded larger results than the corresponding soils in earlier determinations of the loss on ignition. Determinations of the total nitrogen in these samples by the well-known Kjeldahl method were made, but in no case were quantities found sufficiently large to make it necessary to guard against nitrogen in the operations to be described. The amounts of carbon dioxide liberated by dilute sulphuric acid were also determined, and, when necessary, have been allowed for in the data given in this paper. The amounts of carbon dioxide thus liberated by dilute acid in these particular soils are so small that it was not considered necessary to remove this substance before proceeding with certain of the operations to be presently described. In the case of samples, containing much carbonates of the alkalies or alkaline earths, it might be found clesirable to follow the suggestion of Manning ${ }^{1}$ and treat the moistened sample with sulphurous acid before proceeding to a determination of the organic matter, although other procedures 
also suggest themselves, which, for some conditions, are probably more advisable.

Brief descriptions of the samples used in this investigation, together with the amounts of total nitrogen, and carbon dioxide liberated by dilute acid, are brought together in Table $I$.

TABLE I.-Description of Solls and Subsolls with Percentages of Combined Carbon Dioxide and Total Nitrogen.

\begin{tabular}{|c|c|c|c|c|}
\hline $\begin{array}{c}\text { Sample. } \\
\text { No. } \\
4248\end{array}$ & $\begin{array}{l}\text { Description. } \\
\text { Conowingo clay, east of Pilot, } \mathrm{Md} \text {.. }\end{array}$ & $\begin{array}{l}\text { Depth. } \\
0^{\prime \prime}-8^{\prime \prime}\end{array}$ & $\begin{array}{c}\text { dioxide } \\
\text { combined, } \\
\text { Per centt. } \\
\text { o.10 }\end{array}$ & 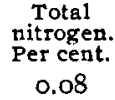 \\
\hline 4249 & & $8^{\prime \prime}-48^{\prime \prime}$ & 0.17 & 0.12 \\
\hline 5223 & $\begin{array}{r}\text { Cecil sandy loam, } 2^{1 / 2} \text { miles south of } \\
\text { Raleigh, N. C.............. }\end{array}$ & $\alpha^{\prime \prime}-8^{\prime \prime}$ & 0.00 & 0.08 \\
\hline 5224 & & $8^{\prime \prime}-36^{\prime \prime}$ & 0.02 & 0.06 \\
\hline $586 \mathrm{I}$ & 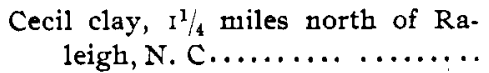 & $\alpha^{\prime \prime}-$ & 0.06 & 0.10 \\
\hline 5862 & & $6^{\prime \prime}-36^{\prime \prime}$ & 0.06 & 0.04 \\
\hline
\end{tabular}

COMPARISON OF RESULTS BY VARIOUS METHODS.

In Table II are given the results of the determinations of organic matter made in the several ways indicated.

TABLE II.-Comparison of Organic Matter, Humus, and Loss on IGNITION.

\begin{tabular}{|c|c|c|c|c|c|}
\hline $\begin{array}{c}\text { Sample } \\
\text { No. }\end{array}$ & $\begin{array}{l}\text { Loss on } \\
\text { ignition. } \\
\text { Per cent. }\end{array}$ & $\begin{array}{l}\text { Humus, } \\
\text { official } \\
\text { method. } \\
\text { Per cent. }\end{array}$ & $\begin{array}{l}\text { Humus, } \\
\text { using } \\
\text { pump. } \\
\text { Per cent. }\end{array}$ & $\begin{array}{c}\text { Combustion, } \\
\text { in tube, } \\
\mathrm{CO}_{2} \times 0.471 \\
\text { Per cert. }\end{array}$ & $\begin{array}{l}\text { Combustion, } \\
\text { wet way, } \\
\mathrm{CO}_{2} \times 0.47 \mathrm{r} \\
\text { Per cent. }\end{array}$ \\
\hline 4248 & $3.9^{2}$ & 1.27 & 0.47 & 0.87 & 0.67 \\
\hline 4249 & 6.67 & I. 40 & 0.70 & 0.97 & 0.74 \\
\hline 5223 & $3.5^{8}$ & 1.30 & 0.70 & 2.26 & I. 75 \\
\hline 5224 & 7.63 & 3.45 & 0.30 & 1.47 & 0.68 \\
\hline $586 \mathrm{I}$ & 6.76 & 2.05 & 0.90 & 2.54 & 2.18 \\
\hline 5862 & II. 98 & 2.80 & 0.15 & 0.98 & $0.3^{8}$ \\
\hline
\end{tabular}

The results given under "loss on ignition" were obtained by heating the test samples in a muffle furnace at a temperature of about $800^{\circ} \mathrm{C}$, using platinum dishes, and recarbonating by putting the moistened soils in a chamber filled with carbon dioxide under a pressure of three atmospheres. It has frequently been found necessary to resort to such high temperatures in order to secure complete combustion of the organic matter, but an element of importance is sometimes involved, for in certain soils some iron is apparently reduced to the metallic condition, and then amalgamates with the platinum dishes. In several instances, serious damage has been done in this way, and a word of caution 
is deemed worth while in this connection. When the results obtained by this method are compared with those given in the other columns, two points immediately strike the attention. First, they are all remarkably high, and if the other methods give any true index of the organic matter present, results by this method may obviously give entirely untrustworthy notions as to the composition of the samples. The second point is that in these particular cases the subsoils invariably yielled higher figures than the soils. This point will be discussed more fully at another place, but it is of importance here to point out that it does not give a true index of the relative amounts of organic matter in the soils and subsoils respectively, and this fact is thus another valid and important objection to the use of the method.

In the next column are given the results for humus obtained by the method of the Association of Official Agricultural Chemists. The figures, while very much lower than those in the column headed "loss on ignition," nevertheless show the same result, that the subsoils contain more organic matter or humus than the corresponding soils. But it was found in the course of these determinations that it was practically impossible to precipitate the fine sediment and clay, the flocculation of which was destroyed by the ammonia solution. Therefore, portions of the ammonia extracts were filtered through the porcelain tube of a Pasteur-Chamberland filter, by means of a simple arrangement of a Bunsen filter flask and a good water aspirator. Proper precautions were, of course, taken to have no contact of the solution with rubber connections and discard first rumings from the filtertube, etc. It is not certain that sone of the dissolved humus may not have been absorbed or otherwise removed from the solution by this procedure, but we had no evidence that such was the case, and believe that any error from this source must have been relatively small. Humus determinations on aliquot portions of the clear solutions thus obtained were carefully made, and the results are given in the table. In every case they are much smaller than when the official method was followed literally, and the conclusion seems inevitable that the higher values were occasioned by the loss of water or volatile materials other than humus, in the ignition of the clay and sediment obtained on drying the ammonia solution extracts. Another point is that in this last 
column of figures we no longer find higher values for the subsoils than for the corresponding soils, except in the first pair. Since these results were believed to give a more accurate idea of the constitution of the soils than those previously described, but could not be regarded as satisfactorily giving quantitative ideas as to the whole amounts of organic matter present, and in view of the well-known wide divergence of opinion as to the value of humus determinations, it was decided to investigate the soils by the combustion method. Moreover, humus determinations are, at the best, tedious to make, especially if recourse must be had to the filter, and as it is very desirable in our work to make annually a very large number of determinations of the organic matter in soils, it was the more desirable to see what could be done with a combustion method. We first employed the regular method of burning the soil in a tube in a combustion furnace. The sample, which was generally about 2 grams in weight, was mixed with several times this weight of well-pulverized black oxide of copper, and the two thoroughly incorporated by grinding and stirring in an agate mortar. The usual precautions were observed in the burning, sweeping out the last traces of carbon dioxide from the tube, making weighings, etc. It was not deemed worth while to put in a guard for nitrogen or chlorides. The figures given in Table II are averages of duplicate determinations. Here again the Conowingo clay appears to contain more organic matter in the subsoil than in the soil, but the reverse is the case with the other soils examined. It is worthy of note also, that in the majority of cases the figures found are less than those obtained for humus by the official method, but are greater in every case than the corresponding figures for humus obtained when the filter was used.

Two objections to this method became patent in its use. It is obviously a matter of extreme difficulty and uncertainty to get a fair sample of soil of as small a weight as 2 grams. Larger quantities than this could not be advantageously handled in a combustion tube, however, and no other reliable form of apparatus suggested itself. Again, a combustion in a tube is necessarily a slow process, and much time which the operator cannot employ otherwise to advantage, is lost in the gradual heating and cooling of the tube necessary for its satisfactory use. A possible third objection, which we believe from our work has an actual exist- 
ence, is the liberation of carbon dioxide other than that combined as carbonates of the alkaline earths, or formed in the combustion of the organic matter. This point will be more fully discussed presently.

\section{THE CHROMIC ACID METHOD.}

From the facts just presented, it was deemed advisable to study other methods. Two wet methods suggest themselves, oxidation with chromic acid or with potassium permanganate. Both of these methods have been tried to some extent. ${ }^{1}$ The chromic acid method presents the lesser amount of manipulation, fewer analytical difficulties, and would seem to be more certain in its oxidation of the organic matter. Therefore, it alone was used in this investigation. The combustion was effected in a round-bottomed flask of about $400 \mathrm{cc}$. capacity, fitted with a 3 -hole rubber stopper. The stopper was fitted with a dropping funnel, a tube for the introduction of air previously freed from carbon dioxide, and a tube leading through a condenser to a train of absorption bulbs. This train contained, first, a Peligot tube containing a saturated and slightly acidified solution of silver sulphate to absorb both hydrochloric acid and sulphur tri-or dioxide should they be generated; then a guard tube containing concentrated sulphuric acid, followed by a potash bulb and acid bulb to be weighed with the potash bulb. The whole apparatus was attached to an aspirator so that air free from carbon dioxide could be drawn through the combustion flask and train. The procedure is as follows:

A sample of the soil, usually about Io grams, is carefully weighed and brought into the combustion flask. If the sample be rich in organic matter, it has been found advisable to introduce also some sand, previously ignited before the blast, and in an amount dependent roughly upon the apparent quantity of organic matter in the soil. From 5 to Io grams of pulverized potassium bichromate are then added, and the whole mixed thoroughly by shaking, care being taken to prevent any of the mixture adhering to the sides of the flask, above the level of the mixture. The flask is closed securely by the stopper, and a gentle stream of air drawn through the whole apparatus by means of the aspirator. When this stream of air has been passing for about ten minutes, concentrated sulphuric acid (sp. gr. about I.83) is slowly and cautiously run in by means of the dropping

\footnotetext{
, Wiley's "Principles and Practice of Agricultural chemical Anulysis," Vol. 1, p. 316.
} 
funnel until the tip of the glass tube, for the introduction of air, is covered. When this point has been reached, and if no very vigorous action is taking place, the combination flask is slowly heated until the sulphuric acid commences to give off fumes. It is held at this temperature for from five to ten minutes, and then allowed to cool slowly, unless there is reason to believe combustion has not been complete, in which case the temperature is again raised. Care must be exercised to see that a steady current of air be kept passing through the apparatus, and that the mixture in the flask be not forced back towards the wash-bottles. If necessary, quite a rapid stream can be drawn through the absorption bulbs without much risk of losing the determination. It is advisable to have the bulb of the dropping tube empty, before commencing the heating, so that the tube can be quickly opened. In over four hundred experiments with this method the flask broke but once, and then the dropping-funnel could not be opened because it contained a quantity of sulphuric acid. A sudden large increase of pressure was generated in the flask, owing to faulty manipulation. The dangerous character of such an accident is sufficiently obvious, but with ordinary care, liability of its occurrence is extremely small.

\section{MODIFICATIONS FOR SOILS CON'TAINING CHLORIDES AND}

\section{CARBONATES.}

In many soils from arid, semi-arid, or marshy areas, there is a considerable content of chlorides. By following the procedure just described with these soils, chlorine gas may be generated, which would be collected in the potash bulbs, forming a mixture of the chloride and hypochlorite in proportions difficult to accurately estimate, and vitiating any attempt to determine the amounts of carbon dioxide absorbed. We have made a number of attempts to get around this difficulty, and have found that it can be met quite simply. If the bichromate of potash be not mixed with the sample before running in the concentrated sulphuric acid, but be dissolved in the acid itself and the solution be slowly and cautiously run in upon the soil, with no attempt to heat the mixture until the reaction in the flask has proceeded for some time, no hydrochloric acid, chlorine, nor chromyl chloride gas is generated, or in but very small amounts. The procedure thus modified has been used a large number of times with 
artificial mixtures and natural soils, and has proved satisfactory, although no explanation is obvious why hydrochloric acil should not be formed and oxidized under these conditions. We can only say that, although we discovered the fact empirically, we have thoroughly tested it with the most gratifying results for the method.

When the amount of chlorides is relatively large, it has sometimes been found desirable to treat the sample with a small volume of dilute sulphuric acid, adding more acid in small quantities from time to time, if necessary, to digest on the steam-bath until the major part of the hydrochloric acid has been removed, and to evaporate as much of the water remaining as can be done without permitting a noticeable action of the solution upon the organic matter. The combustion is then carried out as above described.

With soils which contain carbonates of the alkalies or alkaline earths, it would probably be found satisfactory, as indicated above, to first treat with sulphurous acid to decompose the carbonates, and drive out the carbon dioxide, without oxidizing the organic matter and then to get rid of the water and sulphurous acid by evaporating to dryness before proceeding with combustion.

This method presents, however, a number of difficult manipulations, and requires a great deal of time. It has been found, in the experience of this laboratory, much more convenient to make a separate determination of the carbon dioxide liberated from carbonates, by treating a separate sample of the soil with dilute sulphuric acid ( $1: 6$ by volume), and subtracting the amount thus found from the tota: obtained in the combustion. While this method is not entirely free from objections for very accurate work, it does unquestionably lead to values with all the accuracy necessary for most purposes to which the determination of the organic matter in a soil is applicable.

\begin{tabular}{|c|c|c|c|c|}
\hline Substance. & $\begin{array}{l}\text { Weight } \\
\text { taken, } \\
\text { Gran. }\end{array}$ & $\begin{array}{l}\text { Carbon } \\
\text { dioxide } \\
\text { found. } \\
\text { Gram. }\end{array}$ & $\begin{array}{l}\text { Weight } \\
\text { found. } \\
\text { Graml. }\end{array}$ & $\begin{array}{l}\text { Per cent. } \\
\text { recovered. }\end{array}$ \\
\hline Sugar, $\mathrm{C}_{12} \mathrm{H}_{22} \mathrm{O}_{11} \ldots \ldots \ldots \ldots$ & 0.5026 & 0.7669 & 0.4984 & 99.16 \\
\hline Cellulose, $\mathrm{C}_{12} \mathrm{H}_{20} \mathrm{O}_{10} \ldots \ldots \ldots$ & $\begin{array}{l}0.4405 \\
0.4300\end{array}$ & 0.6633 & 0.4073 & 94.7 \\
\hline & 0.4232 & $0.627^{2}$ & 0.3849 & 90.9 \\
\hline & 0.4135 & 0.6255 & $0.3^{8} 4^{\circ}$ & 92.8 \\
\hline & 0.3714 & 0.5680 & 0.3487 & 93.9 \\
\hline & 0.3430 & 0.5205 & 0.3192 & 93.0 \\
\hline
\end{tabular}




$\begin{array}{ccccc}\text { Substance. Formula. } & \begin{array}{c}\text { Weight } \\ \text { taken. } \\ \text { Gram. }\end{array} & \begin{array}{c}\text { Carbon } \\ \text { dioxide } \\ \text { found. } \\ \text { Gram. }\end{array} & \begin{array}{c}\text { Weight } \\ \text { found. } \\ \text { Gram. }\end{array} & \begin{array}{c}\text { Per cent. } \\ \text { recovered. }\end{array} \\ \text { Urea, } \mathrm{CH}_{4} \mathrm{~N}_{2} \mathrm{O} \ldots \ldots \ldots \ldots \ldots & 0.7858 & 0.5590 & 0.7636 & 97.17 \\ & 0.7090 & 0.4990 & 0.68 \mathrm{I} 6 & 96.14 \\ \text { Asparagine, } \mathrm{C}_{4} \mathrm{H}_{8} \mathrm{~N}_{3} \mathrm{O}_{3} . \mathrm{H}_{2} \mathrm{O} \ldots & 0.5035 & 0.5945 & 0.507 \mathrm{I} & 100.7 \mathrm{I} \\ & 0.4704 & 0.5600 & 0.4776 & 101.53 \\ \text { Sulphanilic acid, } \mathrm{C}_{6} \mathrm{H}_{7} \mathrm{NSO}_{3} \ldots & 0.4080 & 0.6220 & 0.4080 & 100.0 \\ & 0.2115 & 0.320 \mathrm{I} & 0.2100 & 99.29\end{array}$

TEST OF THE CHROMIC ACID METHOD WITH KNOWN ORGANIC SUBSTANCES.

Objection has been urged to the method, that it does not, or at least may not, give accurate results, because some organic substances are not completely oxidized by the chromic acid mixture. With some organic compounds and with the chromic acid mixture as generally used, $i$. e., containing one or more parts of water to every three of sulphuric acid, this is unquestionably true, even when the temperature is raised considerably. But when the procedure is followed, in which only a minimum of water is present, derived from the hydroscopic water in the soil, from the bichromate used, and the product of combustion, it is not believed such an error enters. To test this point, various organic substances of widely different characteristics were burned according to the method just described. In order to distribute the acid mixture, the substance under examination and the bichromate of potash were shaken up with from Io to 15 grams of ignited sand, after being introduced into the flask. The results are given in Table III. While in some instances, certainly, these results cannot be considered as entirely satisfactory determinations when compared with the standard obtainable by the regular method of burning in a tube, they do show that very fair results are obtained, and that there is no reason to expect such phenominally low results as have been reported by other analysts when employing a wet combustion. Sulphanilic acid, for instance, when treated with the chromic acid mixture as commonly used, as is well known, is largely converted into quinone, but no difficulty was experienced in burning it completely, with such satisfactory results, as the figures in the table show.

The cellulose used was a sample of "double washed, ashless" filter-paper. The values obtained with this substance, as shown in the last column of the table, were so low that two combustions of it were made in the tube in the regular way, with the result 
that 96.9 per cent. and 96 per cent. of the amounts taken were recovered as calculated from the weights of carbon dioxide obtained. Evidently this particular substance we had was not well chosen as a representative sample of cellulose, and the figures given in the table are actually better than they appear, though showing an undoubted tendency to run low.

The sample of urea used had been standing a long time in the laboratory. A small portion was recrystallized, and this product gave a much more satisfactory figure for the single combustion of it which was made; but it was believed to be more satisfactory to give the two results from the original sample as showing that the method would give concordant results, especially as we had other results for nitrogenous compounds which showed that the method could be relied upon for this class of substances.

COMPARISON OF COMBUSTIOXS BI THE TLBE AND CHROMIC ACID METHODS.

Combustions of the soils were then made. The averages from the cletcrminations are given in Table II for the sale of making a more ready comparison with the other data founcl. The results of the individual determinations, together with those made in the tube are, however, presented in Table IV.

It should be observed, however, that the results as stated are in terms of percentages of organic matter and conseculuenty involved the use of the factor 0.471 , whereby the discrepancies are made to appear less than half of those actually obtained in percentages of carhon dioxide.

TABIE IV,-COMPARISON OF WET AND DRY COMBUSTIONS OF ORGANIC MATTHR IN SOIIS.

\begin{tabular}{cccccc}
$\begin{array}{c}\text { Sample. } \\
\text { No. }\end{array}$ & \multicolumn{2}{c}{ In tube. } & \multicolumn{3}{c}{ Wet way. } \\
4248 & 0.79 & 0.94 & 0.66 & 0.69 & 0.65 \\
4249 & 0.97 & $\ldots$ & 0.68 & 0.79 & $\ldots$ \\
5223 & 2.15 & 2.36 & 1.71 & 1.79 & $\ldots$ \\
5224 & 1.47 & $\ldots$ & 0.73 & 0.62 & $\ldots$ \\
$586 \mathrm{I}$ & 2.50 & 2.57 & 2.16 & 2.19 & $\ldots$ \\
5862 & 0.98 & $\ldots$ & 0.37 & 0.38 & 0.39
\end{tabular}

It will be observed that, on the whole, better agreements were obtained by the combustions in the wet way; but, as found by analysts who have worked upon this subject, the wet way leads uniformly to lower results than the combustions in the tube. Combustions in the tube in the hands of competent analysts have 
come to be regarded as almost absolute, and therefore great discredit has hitherto been cast upon combustions of soils made in the wet way. This appears to be unjust to the latter method, for the high temperature attained in the combustion tube may be expected to drive out some carbon dioxide, not derived from the oxidation of the organic matter. Ever since the classical work of Bunsen, the difficulty of getting rid of absorbed carbon dioxide except at very high temperatures, has been recognized. The minute cracks and fissures in the small rock and mineral fragments which go to make up a soil are known to contain, frequently, small amounts of carbon dioxide, which are much more likely to be given off in the highly heated combustion tube than in the wet combustion. But probably more important is the carbon dioxide combined with the iron compounds, prevalent in most soils. It will be admitted at once that the existence of iron carbonates or hydrated carbonates in the soil has, so far as we are aware, never been satisfactorily demonstrated, and that the weight of mineralogical evidence is rather against it. That carbon dioxide plays a tremendous role in the solution, transportation and redeposition of iron in the soil, can be scarcely doubted by any one who has given consideration to the subject. That some carbon dioxide would be held by these compounds, either mechanically occluded or actually in chemical combination, seems altogether probable. Such amounts of carbon dioxide would be expected to be liberated readily in the combustion tube, but not at all or not so readily in the wet method. The carbonates of iron are either not readily attacked by concentrated sulphuric acid, or only on prolonged boiling, and the mechanically held carbon dioxide would naturally be expelled much less readily in this medium than in the highly heated tube. To test this point, the soils were first burnt in the wet way. They were then filtered as rapidly as possible in Gooch crucibles, fitted with mats made from asbestos fibers, which had been thoroughly ignited before the blast-lamp. They were then washed free from sulphuric acid, as rapidly as possible, by successive small portions of distilled water. Examining by a powerful magnifying glass, in no case could any traces of organic substances be found in the residues. The residues were then dried at $110^{\circ}-120^{\circ} \mathrm{C}$, placed in a combustion tube and burned in the usual way, proper care being taken, of course, to free the apparatus from carbon dioxide before 
commencing the burning. A portion of the original sample in each case was taken for a combustion in the tube in the usual manner. The results of this work, calculated as percentage of organic matter in the soil, using the factor $0.47 \mathrm{I}$, are given in Table $\mathrm{V}$.

TABLE V.

$\begin{array}{cccccc}\text { Sample. } & \begin{array}{c}\text { Combustion } \\ \text { with } \\ \text { No. }\end{array} & \begin{array}{c}\text { Combustion } \\ \text { chresidue } \\ \text { int tube. }\end{array} & \text { Sum. } & \begin{array}{c}\text { Combustion } \\ \text { intube. }\end{array} & \text { Difference. } \\ 4248 & 0.69 & 0.24 & 0.93 & 0.94 & +0.01 \\ 4249 & 0.79 & 0.17 & 0.96 & 0.97 & -T-0.01 \\ 5223 & 1.71 & 0.42 & 2.13 & 2.15 & -10.02 \\ 5224 & 0.73 & 0.49 & 1.22 & 1.46 & -0.24 \\ 5861 & 2.19 & 0.20 & 2.39 & 2.49 & +-0.10 \\ 5862 & 0.39 & 0.37 & 0.76 & 0.97 & -0.21\end{array}$

In every case, the combustion of the residue from treatment in the wet way gave a surprisingly large increase. Taking the figures obtained as a whole, the idea seems to be amply confirmed that the combustion in the tube cloes yield a large amount of carbon dioxide not derived from the burning of the organic matter. The amounts obtained on the recombustions are certainly astonishing when one considers the relatively small amounts of carbon dioxide obtained from these soils by digestion in dilute acid as given in Table I. That the gas, which is thus given off and collected in the potash bulbs, could be anything else than carbon dioxide, does not seem possible.

PERCENTAGE OF CARBON IN THE HUMUS OF AMERICAN SOILS.

In view of the conflicting statements which exist as to the amount of carbon contained in the humus of soils, and the wide variation in the figures given for this amount, it was deemed advisable to make some investigation on this point with special reference to American soils.

There was available for this purpose a collection of typical agricultural soils prepared by the Bureau for the purposes of comparison, illustration and instruction. The humus was obtained from these soils in the usual way, treating them with hydrochloric acid, removing all traces of chlorides by washing with water and then extracting with 3 per cent. ammonia solution. In the vast majority of cases, the ammoniacal extract which could be decanted from the residue of soil, contained so much suspended material that it was impracticable to work upon it. Therefore it 
was put through a Chamberland-Pasteur filter by which means a perfectly clear solution was obtained free from clay and other suspended material. An aliquot part of this solution was then placed in a weighed platinum dish, carried to dryness on the water-bath and desiccation completed by placing the dish in the hot air oven at $105^{\circ}$ until constant weight was obtained. The differences between the two weights thus obtained are given in the second column of Table VI. The residue was ignited carefully until all signs of the presence of organic matter had disappeared, and the dish was again weighed, by which means it was possible to obtain the ash from the humus extract which in all cases was found to be considerable. In the third column of the table are given the percentages of the humus in the soils corrected for the ash residues which were obtained. These figures, therefore, represent presumably only the organic matter of the humus.

TABLE VI.-PERCENTage of Humus and Carbon in Humus of Typical SoILS OF THE UNited STATES.

$\begin{array}{cccc}\begin{array}{c}\text { Sample } \\ \text { No. }\end{array} & \begin{array}{c}\text { Per cent. of } \\ \text { humus, fitrate. }\end{array} & \begin{array}{c}\text { Per cent. } \\ \text { of humus. }\end{array} & \begin{array}{c}\text { Per cent. of } \\ \text { carbon in humus. }\end{array} \\ 6552 & 0.77 & 0.4 \mathrm{I} & 43.10 \\ 2806 & 0.34 & 0.19 & 37.20 \\ 3994 & 0.86 & 0.63 & 40.65 \\ 3964 & 0.48 & 0.35 & 44.10 \\ 4012 & 0.6 \mathrm{I} & 0.46 & 46.21 \\ 4000 & \mathrm{I} 2.18 & 1 \mathrm{I} .08 & 48.10 \\ 2809 & 0.39 & 0.09 & 40.3 \mathrm{I} \\ 6035 & 2.33 & 2.05 & 49.22 \\ 6550 & 0.20 & 0.09 & 44.00 \\ 3966 & \mathrm{I} .66 & 1.30 & 48.6 \mathrm{I} \\ 6548 & 0.36 & 0.16 & 43.46 \\ 3959 & 0.39 & 0.32 & 33.30 \\ 86 & 0.58 & 0.37 & 34.9 \mathrm{I} \\ 655 \mathrm{I} & 0.26 & 0.08 & 33.30 \\ 3956 & 0.59 & 0.47 & 50.09 \\ 3663 & \mathrm{I} 67 & 0.26 & 44.30 \\ 2808 & 0.54 & 0.28 & 36.22 \\ 279 \mathrm{I} & 0.32 & 0.18 & 37.4 \mathrm{I} \\ 6547 & 0.23 & 0.14 & 39.20\end{array}$

Another portion of the ammoniacal filtrate was carried to dryness and the residue was then taken for the combustion analysis. Combustions of these residues were made both in the tube by the usual method and also by the wet method described in this paper, with satisfactory agreement. The percentages of carbon in the 
humus obtained from these combustions and corrected for the ash, are given in the last column of the table.

It will be seen by an inspection of this table that the percentage of carbon in the humus is much lower than the figures usually accepted, averaging about 42 per cent. instead of 56 per cent., the figure accepted by Wollny, Wolf, von Bemmelen and other authorities.

This would lead to the use of a much higher factor in the calculation of organic matter in the soil than the one employed by these investigators and used in this paper, but it does not seem desirable to advocate this higher factor. While it is probably true, as the figures here presented show, that the percentage of carbon in the humus is lower than the figure set by the authorities cited, nevertheless the amount of humus present in the soil which is extracted by ammonia, after treating with hydrochloric acid is by no means (in the majority of cases) a very large part of the total organic matter present. Furthermore, this organic matter, not extracted by the ammonia, is made up largely of cellulose or cellulose-like substances in which the percentage of carbon approaches closely the figure given by van Bemmelen.

It is impossible, in the present state of our knowledge, to suggest a fair average between the factors derived from these varying data. Inasmuch as the percentages of carbon in the soil calculated by the varying factors do not differ very much from one another, or yield differences which cannot be intelligently interpreted, it seems wisest, on the whole, to retain the factor $0.47 \mathrm{I}$, insisting that it is a conventional factor, and that consequently the organic matter in the soil determined by its use cannot be regarded as anything more than an approximation to the truth by a purely conventional method.

THE ASH OR MINERAL CONSTITUENTS OF HUMUS.

It seems worth while here to call attention to the considerable amounts of mineral matter dissolved in the ammoniacal extract, a large part of which is probably in organic combination. This material is unquestionably in solution, for the filtrates obtained after passing from the Chamberland-Pasteur filter are absolutely clear and free from suspended solids.

It is uncertain how much of this mineral material was in combination with the dissolved organic matter, but judging from the 
figures obtained, it seems quite likely that it was largely of this nature, and it is interesting in view of the accepted practice of treating the soil with hydrochloric acid for the purpose of separating the humus bodies from the mineral constituents before extracting with ammonia.

A number of these ash residues were examined qualitatively, and in the majority of cases they were found to be made up principally of iron oxides, alumina, and silica. In several cases, considerable manganese was present in the ash, but the most striking point brought out was that in the case of certain of these soils there was unquestionably lime in the ash from the filtrate, in spite of the fact that these soils had been carefully extracted with dilute hydrochloric acid before treatment with the ammonia solution.

In the case of a residue obtained from soil No. 2809 , the ash from the ammoniacal filtrate was mainly lime.

\section{CONCLUSIONS.}

( I) The conclusion seems inevitable that the combustion of a soil in the wet way with the chromic acid mixture, as described in this paper, will give a more accurate idea of the organic matter in the soil than any other method we have seen described. The method, moreover, is a fairly rapid one. It is found by considerable experience that such a combustion requires on the average about forty minutes for all operations, once the apparatus has been assembled, and that one man, working as rapidly as is consistent with good work, can make six to seven such determinations in a working day of seven hours. He can hardly make more than two satisfactory determinations in the combustion tube in the same length of time, using but one outfit.

(2) As a result of a large number of determinations, which have now been made by the combustion method here described, it may be said that the organic matter in a subsoil rarely equals or exceeds that contained in the corresponding soil.

(3) The facts presented here would suggest that the humus determination is of even more uncertain value than is usually believed.

(4) There is not sufficient ground as yet for advocating the use of any other factor than the usually accepted one for the calculation of the organic matter from the carbon dioxide obtained in the combustion. 